Article

\title{
Effect of Addition of PVA/PG to Oil-in-Water Nanoemulsion Kojic Monooleate Formulation on Droplet Size: Three-Factors Response Surface Optimization and Characterization
}

\author{
Nur Farzana Jaslina ${ }^{1,2}\left(\mathbb{D}\right.$, Nur Hana Faujan ${ }^{1,2,3}$, Rosfarizan Mohamad $4(\mathbb{D}$ \\ and Siti Efliza Ashari 1,2,3,* \\ 1 Integrated Chemical BioPhysics Research, Faculty of Science, Universiti Putra Malaysia, Serdang 43400, \\ Malaysia; farzanajaslina23@gmail.com (N.F.J.); nurhana@upm.edu.my (N.H.F.) \\ 2 Department of Chemistry, Faculty of Science, Universiti Putra Malaysia, Serdang 43400, Malaysia \\ 3 Centre of Foundation Studies for Agricultural Sciences, Universiti Putra Malaysia, Serdang 43400, Malaysia \\ 4 Department of Bioprocess Technology, Faculty of Biotechnology \& Biomolecular Sciences, Universiti Putra \\ Malaysia, Serdang 43400, Malaysia; farizan@upm.edu.my \\ * Correspondence: ctefliza@upm.edu.my; Tel.: +60-(3)-8947-7847
}

Received: 5 July 2020; Accepted: 1 August 2020; Published: 23 September 2020

check for updates

\begin{abstract}
An oil in water (O/W) nanoemulsion formulation containing kojic monooleate (KMO) in thin film system was developed. Response surface methodology (RSM) was used to optimize and analyzed the effect of three variables, namely concentration of polyvinyl alcohol (PVA) (20-30\% w/w), concentration of propylene glycol (PG) $(1-10 \% w / w)$, and shear rate of high shear homogenizer (3000-9000 rpm) on droplet size as a response, while other compositions remained constant such as KMO $(10.0 \% w / w)$, Tween $80(3.19 \% w / w)$, castor oil $(3.74 \% w / w)$, xanthan gum $(0.70 \% w / w)$, and germall plus $(0.7 \% w / w$, PG (and) diazolidinyl urea (and) iodopropynyl butylcarbamate). The optimized KMO nanoemulsion formulation with desirable criteria was PVA $(27.61 \% w / w)$ and PG (1.05\% $w / w)$, and shear rate $(8656.17 \mathrm{rpm})$ with a predicted droplet size $(110.21 \mathrm{~nm})$ and actual droplet size $(105.93 \mathrm{~nm})$ with a residual standard error (RSE) of less than $2.0 \%$ was obtained. Analysis of variance (ANOVA) showed that the fitness of the quadratic polynomial fit the experimental data with a $F$-value of 65.30, $p$-value of $p<0.0001$, and a non-significant lack-of-fit. The optimized KMO formulation shows the desired criteria of the thin film system and the physicochemical properties (Zeta potential $-37.37 \mathrm{mV}$, PDI 0.13, pH 4.74) and stability at four different conditions indicate its suitability for cosmeceutical applications.
\end{abstract}

Keywords: nanoemulsion; formulation; thin film system; response surface methodology; kojic monooleate

\section{Introduction}

A derivative of kojic acid, kojic monooleate (KMO) is non-toxic, soluble in oil, and enhances stability to $\mathrm{pH}$, temperature, and storability compared to kojic acid [1]. KMO also possesses higher 2, 2-diphenyl-1-picrylhydrazyl (DPPH) inhibition, better mushroom tyrosinase inhibition, and B16F1 melanoma tyrosinase inhibition as well as less cytotoxicity compared to kojic acid [2], hence a formulation containing KMO was developed for cosmeceutical application in this study.

To achieve a desired effect on skin, penetration of the active compound into the skin after its topical application is required [3]. Hence, the size of the droplet plays a major role in determining the effect of a formulation on skin. Nanoemulsion drug delivery systems such as lipid based formulations 
that improve the solubility and bioavailability of hydrophobic drugs are the most appropriate for topical applications, considering the composition of the skin structure and its barrier property $[3,4]$. Nanoemulsions are oil-in-water $(\mathrm{O} / \mathrm{W})$ or water-in-oil $(\mathrm{W} / \mathrm{O})$ emulsions with a droplet size range of between 20-200 nm [5-7].

A thin film system may also be used as vehicles for active substances [8]. The polymeric network of the formed film controls the release of the drug substance into the skin [9]. Other studies have mentioned that the film formed provided an occlusion effect and tensor action after drying, thus, making the skin softer to touch [10]. However, it needs to meet several criteria such as adhering to the skin surface, fast drying, and flexibility at skin temperature to be considered as a good thin film system $[9,11]$. Thin film formulations often contain plasticizers, moisturizers, preservatives, surfactants, fragrances, and active substances $[10,12,13]$. To the best of our knowledge, a comprehensive literature review shows that no studies have been conducted on nanoemulsion formulations containing KMO in cosmetic applications.

Response surface methodology (RSM) is often used for modeling, optimization, and analysis because of its ability to evaluate the effects of multiple variables and their interactions toward a response variable using a sequence of designed experiments to obtain an optimal response [14-16]. In addition, RSM provides the maximum information with experimental time and resources as it reduces the number of experiments $[17,18]$. RSM has been widely used in nanoemulsions and pharmaceutical drug delivery to determine the effect of variables such as pressure, oil content, and number of passes of the microfluidizer on particle size [19,20]. Beringhs et al. (2013) also used RSM to optimize thin film formulations containing green clay and aloe vera as active ingredients and polyvinyl alcohol (PVA) as a plasticizer [21].

Thus, the main objective of this work was to develop a nanoemulsion formulation containing $\mathrm{KMO}$ in a thin film system as an active ingredient. RSM was used to optimize the droplet size of the KMO formulation. The effects of the concentration of polyvinyl alcohol and propylene glycol and its shear rate of homogenization toward droplet size was investigated. In addition, characteristic and physicochemical properties of the optimized KMO formulation in the thin film system were also examined.

\section{Materials and Methods}

\subsection{Materials}

Castor oil (CO) and polyvinyl alcohol (PVA) were purchased from Sigma Aldrich, Saint Louis, USA. Ethyl acetate, polyvinylpyrrolidone (PVP, poly (methyl) methacrylate, polyethylene glycol 6000 (PEG 6000), polyethylene glycol 10,000 (PEG 10,000), polyethylene glycol 20,000 (PEG 20,000), isopropyl myristate, glycerol, and $n$-hexane were purchased from Merck, Darmstadt, Germany. Lipase acrylic resin (Novozym 435) was purchased from Novozym, Bagsvaerd, Denmark. Tween 80 and carboxymethyl cellulose were purchased from Fisher, Hampton, USA. Kojic acid, oleic acid, xanthan gum, propylene glycol, hydroxypropyl methyl cellulose (HPMC), and liquid germall plus were purchased of cosmetic grade. Nanocellulose was obtained from the Faculty of Biotechnology, UPM. Deionized water was purified using a Milli-Q water system (EMD Millipore). All chemicals and other reagents used were of analytical, food, and cosmetic grade classes.

\subsection{Selection of the Polymer}

The KMO formulation was formulated according to previously published data [22] with slight modification on the addition of polymer and solvent to develop a thin film system. Few plasticizers were chosen to be incorporated into the KMO formulation, which includes polyvinyl alcohol (PVA), polyvinylpyrrolidone (PVP), poly(methyl) methacrylate, hydroxypropyl methyl cellulose (HPMC), CM-cellulose, and nanocellulose at $1 \%(w / w)$ and the stability (centrifugal force), dosage form, film formation, peelability, and resistance to pressure of the thin film were investigated. 


\subsection{Selection of Solvent}

A few solvents (propylene glycol (PG), polyethylene glycol 6000 (PEG 6000), polyethylene glycol 10,000 (PEG 10,000), polyethylene glycol 20,000 (PEG 20,000), isopropyl myristate, and glycerol) were incorporated individually at $1 \%(w / w)$ into the formulation to enhance the drying time of the thin film. The stability (centrifugal force), dosage form, film formation, peelability, and drying time of the thin film were investigated.

\subsection{Formulation of Kojic Monooleate Nanoemulsion Formulation in Thin Film System (TFS)}

PVA was dispersed in deionized water $\left(1: 1\right.$ ratio) and heated at $80{ }^{\circ} \mathrm{C}$ to dissolve the PVA. For the oil phase, $10.0 \%(w / w)$ KMO was mixed with $3.37 \%(w / w)$ castor oil. For the aqueous phase, Tween 80 $(3.19 \% w / w)$, xanthan gum $(0.70 \% w / w)$, deionized water $(42.74-61.74 \% w / w)$, PVA $(20-30 \% w / w)$, and PG $(1-10 \% w / w)$ were mixed together. Both aqueous and oil phases were stirred continuously while heated at $30{ }^{\circ} \mathrm{C}$ before being subjected to sonication for $20 \mathrm{~min}$ at $70{ }^{\circ} \mathrm{C}$ using an ultrasonic bath sonicator (Power Sonic 405, Hwashin Technology Co., Seoul, Korea). After sonication, the aqueous phase was homogenized while the oil phase was added drop by drop during the homogenization process, which took place for $15 \mathrm{~min}$ at $6000 \mathrm{rpm}$ using a high shear homogenizer (T25 digital; IKA-Werk, $\mathrm{GmbH} \&$ Co. KG, Staufen im Breisgau, Germany) at room temperature. Then, the mixture was further homogenized for $3 \mathrm{~h}$ at $250 \mathrm{rpm}$ using a low-shear homogenizer (RW20 digital; IKA-Werk). Finally, $0.7 \%(w / w)$ of liquid germall plus was added into the mixture and further homogenized for $15 \mathrm{~min}$ at $250 \mathrm{rpm}$.

\subsection{Optimization Using the Response Surface Methodology (RSM)}

\subsubsection{Experimental Design}

Three factors were utilized to study the interaction effects of polyvinyl alcohol (A), propylene glycol (B), and shear rate of a high shear homogenizer (C) on the droplet size. Tween 80, KMO, castor oil, xanthan gum, and deionized water were kept constant [22]. Table 1 shows the constraints of the independent variable proportions. The experimental design was developed using Design Expert software (version 7.1.5; Stat Ease Inc., Minneapolis, USA) presuming a quadratic model with interactions among the variables. Following the experimental design, a total of 20 runs were tested and statistically evaluated. Six replicates of the center point were performed to reduce the impact of noise and to provide the number of degrees of freedom needed for an adequate statistical evaluation of the model.

Table 1. Constraints of independent variable proportions.

\begin{tabular}{cccc}
\hline \multirow{2}{*}{ Levels } & \multicolumn{3}{c}{ Independent Variables } \\
\cline { 2 - 4 } & $\begin{array}{c}\text { Percentage PVA (A) } \\
\mathbf{( \% )}\end{array}$ & $\begin{array}{c}\text { Percentage PG (B) } \\
\mathbf{( \% )}\end{array}$ & $\begin{array}{c}\text { Shear rate (C) } \\
\text { (rpm) }\end{array}$ \\
\hline Lower limit, $\mathrm{L}_{1}$ & 20 & 1 & 3000 \\
Upper limit, $\mathrm{U}_{1}$ & 30 & 10 & 9000 \\
\hline
\end{tabular}

\subsubsection{Statistical Analysis}

Variables resulting in the minimum droplet size were selected as the optimum condition to develop the KMO formulation. Analysis of variance (ANOVA) was done to recognize the effect of single factors, binary interactions, and quadratic terms toward droplet size and to evaluate the significant differences among the independent variables in terms of the lack-of-fit test [23]. The best model can be achieved with the probability value ( $p$-value) that was significant $(p<0.05)$. The equation to predict the droplet size in terms of coded factors can be calculated as in Equation (1): 
where $Y$ is the particle size, and A, B, C represent the independent variables, PVA, PG, and shear rate (rpm), respectively.

\subsubsection{Verification of Models}

Verification of the model was performed to evaluate the competence of the predicted response values. Five random formulations with a different percentage of composition were used to validate the model. The actual and predicted droplet size values and percentage of the residual standard error (RSE) were calculated.

\subsection{Characterization of the Thin Film System (TFS)}

\subsubsection{Film Formation}

The films were formed on a glass slide following the previous method [10]. Film formation was studied and rated as complete or incomplete, uniform or non-uniform, and with or without precipitation of the compositions. The evaluation was observed in terms of transparency or opaque, sticky or dry, peelable or non-peelable.

\subsubsection{Drying Time}

The formulation was applied to the inner sides of the forearm of a volunteer. Then, a glass slide was placed on the film without pressure and the time was recorded. If there was no liquid visible on the glass slide, the film was considered dry [10]. However, if there was remaining liquid on the glass slide, the experiment was repeated with an increase in drying time. A good thin film should have minimum drying times to avoid a long waiting time for the consumer.

\subsection{Physicochemical Characterization}

\subsubsection{Viscosity}

Viscosity is defined as the shear stress divided by the rate of shear strain [24]. The viscosity was determined using a rheometer. The viscosity of KMO formulation, control formulation, and KMO formulation without PVA were measured. The measurement was carried out with $4{ }^{\circ} \mathrm{C} / 40 \mathrm{~mm}$ cone and plate geometries (gap of $0.100 \mathrm{~mm}$ ) at $25^{\circ} \mathrm{C}$. The steady rheological behavior of the samples were analyzed at a controlled rate varying from 0.1 to $100 \mathrm{~s}^{-1}$. The sample was allowed to stand for $10 \mathrm{~min}$ to achieve an equilibrium state prior to measurement. The experimental data were fitted to the power-law model as in Equation (2):

$$
\eta=\mathrm{ky}^{\mathrm{\prime n}-1}
$$

where $\eta$ is the viscosity (Pa.s); $\mathrm{y}^{\prime}$ is the shear rate $\left(\mathrm{s}^{-1}\right)$; and $\mathrm{k}$ and $\mathrm{n}$ are the consistency index and flow behavior index, respectively.

\subsubsection{Droplet Size}

A droplet size analyzer (Zetasizer Nano ZS90; Malvern Instruments, Malvern, UK) was used to measure the droplet size, stability, and size distribution of molecules in the KMO formulation using a dynamic light scattering method, scattered at an angle of $173^{\circ}$ at $25^{\circ} \mathrm{C}$. The samples was diluted with deionized water to obtain a desired concentration and filled into a folded capillary cell (DTS1070; Malvern Instruments) [22]. The count rate was kept between 100 and 300 kcps. The droplet size (20-200 nm) was analyzed based on the intensity weighted distribution (Z-average), while the Zeta potential was determined based on the measurement of the electrophoretic mobility of dispersed particles in a charged field. 


\subsubsection{Transmission Electron Microscopy (TEM)}

The size and morphology of the KMO formulation were investigated using a microscopy technique by transmission electron microscopy (TEM, JEOL JEM-1400Flash; JEOL, Tokyo, Japan). The sample was homogenized in deionized water. A formvar coated copper grid was added on top of a drop of diluted sample and left at room temperature $\left(25^{\circ} \mathrm{C}\right)$ for $3 \mathrm{~min}$. It was then stained using $2 \%$ phosphotungstic acid for $2 \mathrm{~min}$ and air dried prior to analysis.

\subsection{4. $\mathrm{pH}$}

The $\mathrm{pH}$ of the KMO formulation was determined using a Delta $320 \mathrm{pH}$ meter (Mettler Toledo, Columbus, $\mathrm{OH}, \mathrm{USA}$ ). The measurements of the $\mathrm{pH}$ of the formulation were performed in triplicate and the average values were calculated. Calibration with standard buffer solutions at $\mathrm{pH} 4.00,7.00$, and 10.00 was performed before $\mathrm{pH}$ measurements were taken [25].

\subsubsection{Stability Study}

The stability study of the KMO formulation involved stability under centrifugation and thermal stability under storage for 28 days (at room temperature; $25 \pm 1.0^{\circ} \mathrm{C}$ with exposure to sunlight, at room temperature; $25 \pm 1.0^{\circ} \mathrm{C}$, without exposure to sunlight $45 \pm 1.0^{\circ} \mathrm{C}$ and $4 \pm 1.0^{\circ} \mathrm{C}$ ). Duplicate samples of the optimized formulation were stored in opaque polyethylene bottles and submitted to the mentioned storage conditions in order to evaluate the preliminary physicochemical stability. Each sample was analyzed weekly according to various parameters, namely organoleptic characteristic, applicability, film-forming performance, and particle size. For stability under centrifugation, the sample was subjected to heating at $50{ }^{\circ} \mathrm{C}$ for $5 \mathrm{~min}$ before centrifugation for $15 \mathrm{~min}$ at $3000 \mathrm{rpm}$. The stability of the sample was observed.

\section{Results and Discussion}

\subsection{Combination of Polymer and Solvent to Develop KMO Formulation in TFS}

Among the polymers and solvents tested, PVA and PG were chosen to develop the TFS, but further improvement is needed to make the thin film peelable and resistant to pressure. Therefore, PVA and PG were combined in a formulation at various concentrations to find the range of concentration of PVA and PG prior to the optimization process. It was found that the addition of PG was only appropriate at $1-10 \%(w / w)$, since at concentrations of $12.5 \%$ and $15 \%$, the formulations were not stable under centrifugal force. However, the addition of PG does not affect the peelable and resistance of thin film toward pressure. Then, the concentration of PG was fixed at $1 \%$ and $10 \%$ to study the effect of the concentration of PVA on TFS. The concentration of PVA does not affect the stability of the formulation, it only affected the TFS characteristics. At a higher concentration of PVA (20-30\%), the thin film was peelable and showed resistance to pressure. This finding was in agreement with [26] as they mentioned that PVA plays a major role as a plasticizer and film former. Many studies using PVA as a film former to develop TFS included a charcoal peel off film by using 14\% (w/w) PVA and 3\% (w/w) glycerine as a film former and solvent [25]. Another example was a green clay and aloe vera peel-off film developed using 13\% (w/w) PVA and 10\% $(w / w)$ carbomer as the plasticizer [23].

\subsection{Optimization Using the Response Surface Methodology (RSM)}

The optimized droplet size of the KMO nanoemulsion formulation was obtained experimentally using the RSM optimization method as tabulated in Table 2. The table shows that the minimum droplet size obtained was $111.1 \mathrm{~nm}$ (run no. 17). The actual droplet size values were mostly in good agreement with the predicted values. The analysis of variance (ANOVA) results for the effect of three variables were performed to investigate the suitability and significance of the model (Table 3). The model was significant with $F$-value $(65.30)$ and $p$-value $(<0.0001)$, and the lack-of-fit was not significant toward 
the response (droplet size). There is only a $0.01 \%$ chance that a "Model F-Value" could occur due to noise. In this case A, B, C, BC, and $C^{2}$ were significant model terms. The $\mathrm{R}^{2}(0.9866)$ was in reasonable agreement with the adjusted $\mathrm{R}^{2}(0.9715)$, as shown in Table 4 . Adequate precision measures the signal to noise ratio. A ratio of 28.498 ( $>4$ is desirable) indicates an adequate signal.

Table 2. Experimental data and the actual and predicted values of the droplet size of the nanoemulsion obtained from the RSM experimental design model.

\begin{tabular}{cccccc}
\hline & \multirow{2}{*}{ Run No } & PG & PG & Shear Rate & \multicolumn{2}{c}{ Droplet Size (nm) } \\
\cline { 5 - 6 } & A & B & C & Actual & Predicted \\
\hline 1 & 25.0 & 10.0 & 6000.0 & 146.1 & 130.3 \\
2 & 20.0 & 1.0 & 3000.0 & 159.3 & 160.3 \\
3 & 30.0 & 10.0 & 3000.0 & 147.9 & 148.3 \\
4 & 20.0 & 5.5 & 6000.0 & 136.0 & 134.8 \\
5 & 30.0 & 5.5 & 6000.0 & 124.0 & 123.6 \\
6 & 25.0 & 5.5 & 6000.0 & 126.1 & 126.1 \\
7 & 20.0 & 10.0 & 3000.0 & 163.5 & 164.2 \\
8 & 25.0 & 5.5 & 6000.0 & 123.1 & 126.1 \\
9 & 20.0 & 10.0 & 9000.0 & 133.1 & 132.6 \\
10 & 25.0 & 5.5 & 9000.0 & 117.3 & 118.8 \\
11 & 25.0 & 5.5 & 6000.0 & 122.4 & 126.1 \\
12 & 20.0 & 1.0 & 9000.0 & 142.3 & 117.2 \\
13 & 25.0 & 5.5 & 6000.0 & 125.4 & 126.1 \\
14 & 25.0 & 1.0 & 6000.0 & 122.6 & 121.0 \\
15 & 25.0 & 5.5 & 6000.0 & 127.6 & 126.1 \\
16 & 25.0 & 5.5 & 3000.0 & 154.8 & 151.7 \\
17 & 30.0 & 1.0 & 9000.0 & 111.1 & 110.8 \\
18 & 30.0 & 10.0 & 9000.0 & 126.1 & 125.5 \\
19 & 25.0 & 5.5 & 6000.0 & 128.6 & 126.1 \\
20 & 30.0 & 1.0 & 3000.0 & 144.0 & 144.9 \\
\hline
\end{tabular}

Abbreviations: PVA, polyvinyl alcohol; PG, propylene glycol.

Table 3. Analysis of variance (ANOVA) results for the effect of the three variables.

\begin{tabular}{ccccccc}
\hline Source & Sum of Squares & df & Mean Square & $\boldsymbol{F}$-Value & $p$-Value & Significant \\
\hline Model & 3725.55 & 9 & 413.95 & 65.30 & $<0.0001$ & significant \\
A & 208.05 & 1 & 208.05 & 32.82 & 0.0004 & 0.0026 \\
B & 117.19 & 1 & 117.19 & 18.49 & 283.44 & $<0.0001$ \\
C & 1796.80 & 1 & 1796.80 & 0.016 & 0.9012 \\
AB & 0.10 & 1 & 0.10 & 3.80 & 0.0869 \\
AC & 24.11 & 1 & 24.11 & 6.25 & 0.0370 \\
BC & 39.60 & 1 & 39.60 & 3.40 & 0.1023 \\
A & 21.57 & 1 & 21.57 & 0.045 & 0.8375 \\
B & 0.28 & 1 & 0.28 & 29.25 & 0.0006 \\
C & 185.44 & 1 & 185.44 & & 0.4071 \\
Residual & 50.71 & 8 & 6.34 & 1.17 & not significant \\
Lack-of-Fit & 20.96 & 3 & 6.99 & & \\
Pure Error & 29.75 & 5 & 5.95 & & \\
Cor Total & 3776.26 & 17 & 5 & & \\
\hline
\end{tabular}

Notes: The letters A-C represent the independent variables, where A is PVA, B is PG, and C is shear rate (rpm). Abbreviations: PVA, polyvinyl alcohol; PG, propylene glycol; cor total, corrected total sum of squares.

The final equation to predict the droplet size in terms of actual factors can be calculated as in Equation (3):

$$
\begin{gathered}
Y=323.98193-8.23517 \mathrm{~A}+0.15246 \mathrm{~B}-0.022591 \mathrm{C}-6.48485 \mathrm{E}-003 \mathrm{AB} \\
+1.48061 \mathrm{E}-004 \mathrm{AC}+2.10808 \mathrm{E}-004 \mathrm{BC}+0.12524 \mathrm{~A} 2 \\
-0.019753 \mathrm{~B} 2+1.02010 \mathrm{E}-006 \mathrm{C} 2
\end{gathered}
$$

where A, B, C represent the independent variables PVA, PG, and shear rate, respectively. 
Table 4. Regression coefficient estimate results for the effect of the three variables.

\begin{tabular}{cccc}
\hline Factor & Coefficient Estimate & & \\
\hline Intercept & 126.07 & Standard deviation & 2.52 \\
A & -5.60 & Mean & 132.94 \\
B & 4.67 & C.V. $\%$ & 1.89 \\
C & -16.47 & PRESS & 787.73 \\
AB & -0.15 & $\mathrm{R}^{2}$ & 0.9866 \\
AC & 2.22 & Adjusted R & 0.9715 \\
BC & 2.85 & Predicted R & 0.7914 \\
$\mathrm{~A}^{2}$ & 3.13 & Adequate precision & 28.498 \\
$\mathrm{~B}^{2}$ & -0.40 & & \\
$\mathrm{C}^{2}$ & 9.18 & & \\
\hline
\end{tabular}

Notes: The letters A-C represent the independent variables, where A is PVA, B is PG, and C is shear rate (rpm). Abbreviations: PVA, polyvinyl alcohol; PG, propylene glycol.

In this study, the minimum droplet size was the main consideration as nanosizes with a range between 20 and $200 \mathrm{~nm}$ are more desirable for a cosmetic product. Smaller droplet sizes are able to penetrate through the stratum corneum of the skin easily. Therefore, it is vital to maintain the nanosize of the KMO formulation to enhance the penetration of KMO to the skin, without disrupting normal tissues. Therefore, Figures 1-3 show the three-dimensional surface graphs on droplet size. Based on Figure 1, increasing the concentration of PVA will decrease the droplet size. This is because of the ability of PVA to act as a surfactant and capping agent, thus making them capable of modifying the surface of particles and prevent the growth of the particles [27]. The presence of the PVA in the polymerization mixture has strongly influenced the morphology by providing better order and reducing the aggregations of the particles [28].

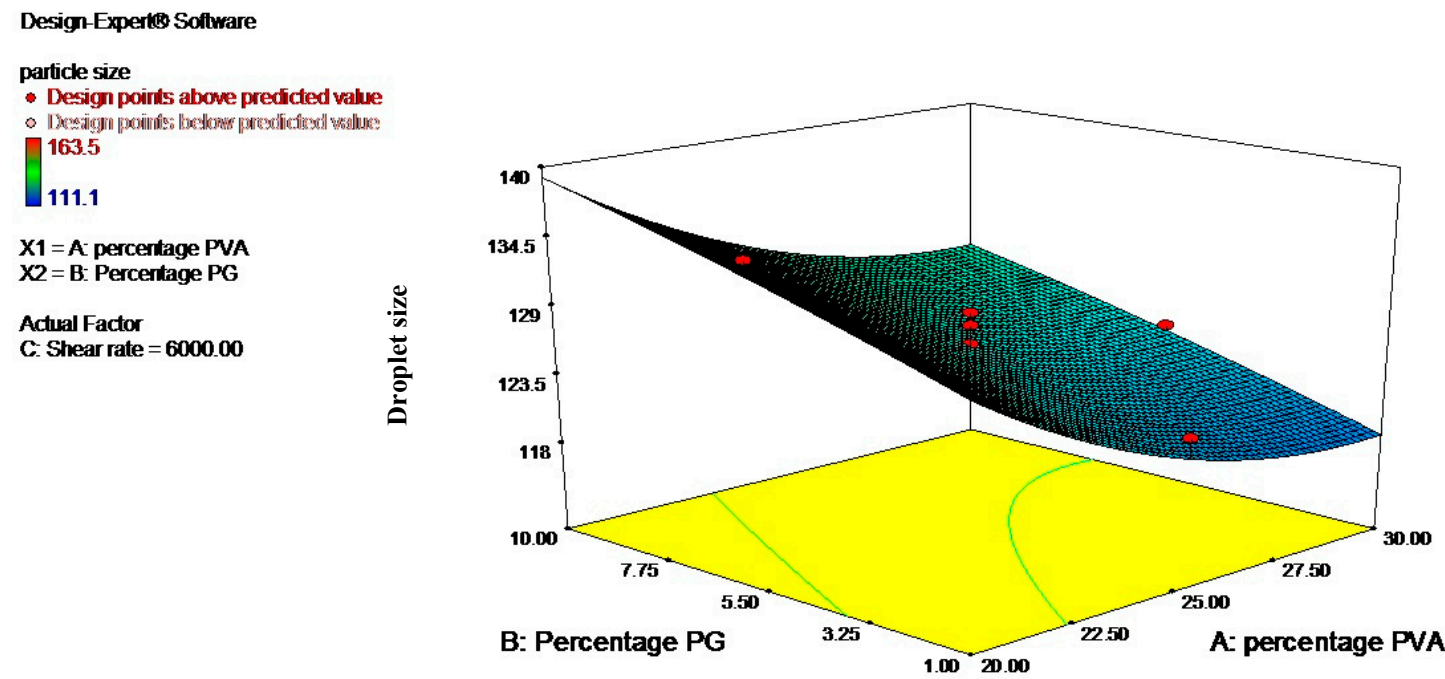

Figure 1. Three-dimensional surface graphs showing the effect of percentage PVA and percentage PG on droplet size; shear rate was kept constant.

Based on Figure 2, the increment of the shear rate caused a decrease in the droplet size. This occurrence has been reported in a previous study that mentioned that the increment of the shear rate speed would decrease the droplet size and increase the size uniformity [29]. At high shear homogenization, the turbulent forces are large, thus able to disrupt the bonds that hold the particles together, and thus deform the flocs and eventually disrupt them. At low shear homogenization speed, the turbulent forces are not large enough to disrupt the bonds and so the droplets can act like flocs with a fixed size and shape [30]. 


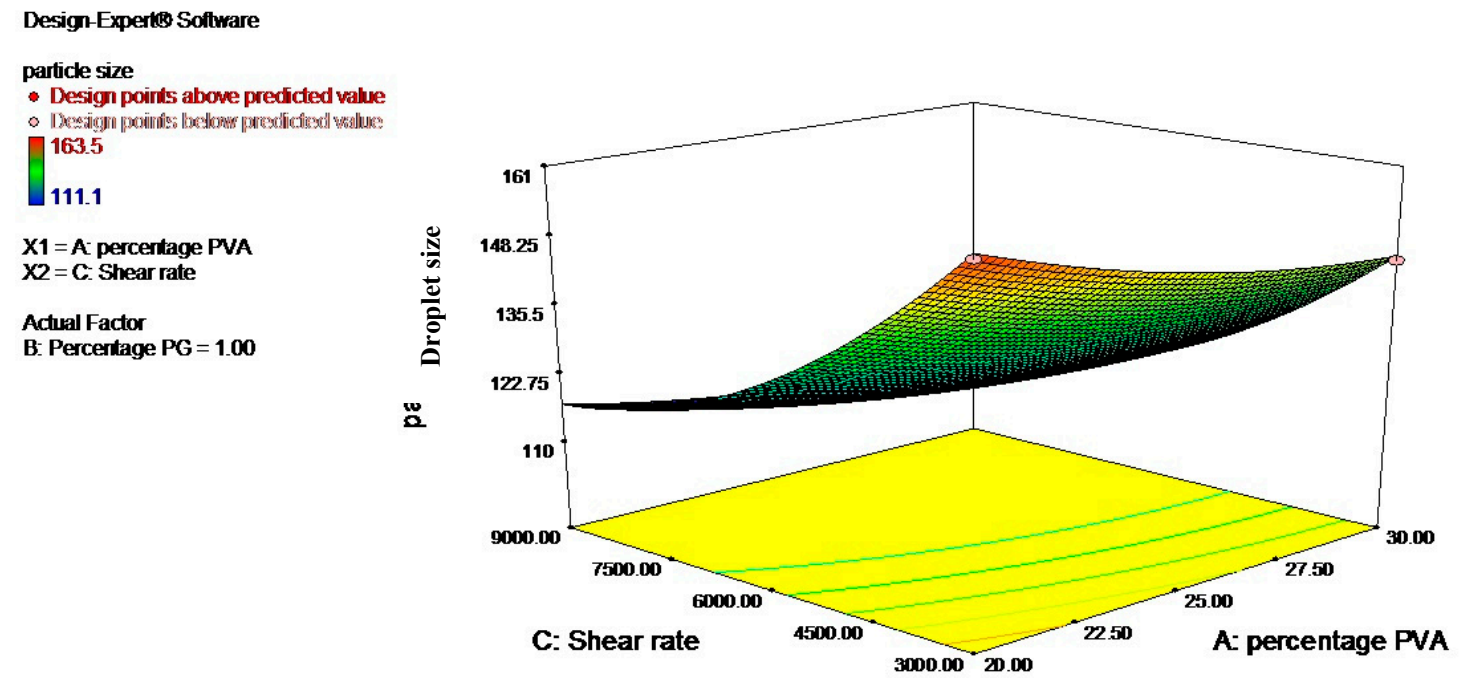

Figure 2. Three-dimensional surface graphs showing the effect of percentage PVA and shear rate on droplet size; percentage PG was kept constant.

In contrast, increasing the concentration of PG will cause the increment of the droplet size (Figure 3). The addition of PG reduced the formation region of the microemulsion and reduced the isotropic region, in which only a small amount of oil and water can be solubilized [31]. On the other hand, other finding have shown that when the concentration of PG was from 0 to 20\%, the droplet size decreased slightly; at 30 to $40 \%$ PG, the droplet size decreased steeply; and at 40 to 50\% PG, the droplet size was slightly increased [32]. Various findings regarding the effect of PG on droplet size may be due to the property of PG, which have two competitive effects: (i) one dissolved in water, which results in the reduction of interactions between droplets, thus lowering the droplet size and (ii) another dissolved in oil, which resulted in the increment of interactions between droplets, making the droplet size bigger [33]. As the increment of PG caused the droplet size to be bigger in this study, it can be concluded that the second effect dominates the first one under the experimental conditions and compositions used.

\section{Design-Experk Software}

particke size
$\begin{aligned} & 163.5 \\ & 111.1\end{aligned}$
$X 1=B$ : Percentage PG
$X 2=$ C. Shear rate

Actual Factor A percentage $\mathrm{PVA}=\mathbf{2 5 . 0 0}$

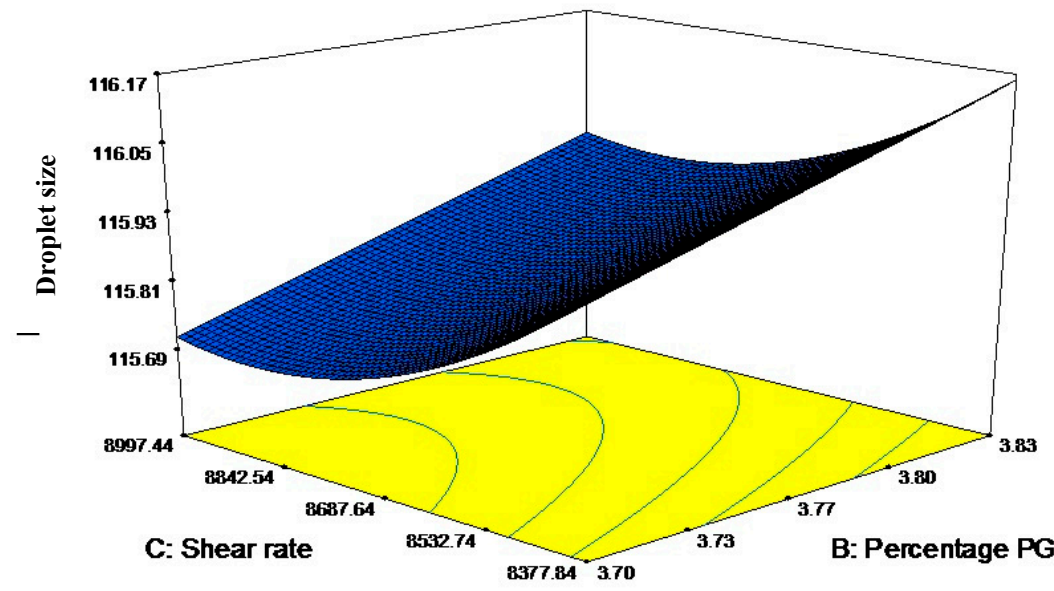

Figure 3. Three-dimensional surface graphs showing the effect of percentage PG and shear rate on droplet size; percentage PVA was kept constant.

The model was validated and the actual and predicted response values of five randomized formulations were evaluated in Table 5. No significant difference between the actual and predicted 
response values was detected, which indicates that the fitness model was developed. Based on the validation set, \% RSE was $<2.00$, which indicated no significant difference between the actual and predicted values and therefore demonstrated that a good model was obtained.

Table 5. Validation set of the KMO nanoemulsion formulation.

\begin{tabular}{|c|c|c|c|c|c|}
\hline \multicolumn{3}{|c|}{ Independent Variables } & \multicolumn{2}{|c|}{ Size Particle } & \multirow[b]{2}{*}{$\begin{array}{l}\text { Relative Standard } \\
\text { Error (\% RSE) }\end{array}$} \\
\hline $\mathbf{A}$ & B & $\mathrm{C}$ & $\begin{array}{l}\text { Actual Value } \\
\text { (nm) }\end{array}$ & $\begin{array}{l}\text { Predicted Value } \\
\text { (nm) }\end{array}$ & \\
\hline 22 & 1 & 9000 & $105.20 \pm 0.36$ & 113.93 & 0.18 \\
\hline 22 & 1 & 8000 & $112.57 \pm 0.64$ & 115.72 & 0.32 \\
\hline 24 & 2.5 & 9000 & $107.23 \pm 1.79$ & 114.38 & 0.91 \\
\hline 24 & 2.5 & 8000 & $110.87 \pm 1.19$ & 115.54 & 0.60 \\
\hline 26 & 5 & 6000 & $122.87 \pm 0.29$ & 124.52 & 0.13 \\
\hline
\end{tabular}

Notes: The letters A-C represent the independent variables, where A is PVA, B is PG and C is shear rate (rpm). Abbreviations: PVA, polyvinyl alcohol; PG, propylene glycol; cor total, corrected total sum of squares.

The results of the predicted values were studied by calculating the RSE as shown in Equation (4):

$$
\operatorname{RSE}(\%)=\frac{\text { Actual value }- \text { Predicted value }}{\text { Predicted value }} \times 100
$$

The optimized formulation was developed to obtain a minimum droplet size of the nanoemulsion (Table 6). Based on Table 7, an optimized formulation with the composition of PVA (27.61 w/w), PG $(1.05 \% w / w)$, and shear rate $(8656.17 \mathrm{rpm})$ was suggested with a predicted droplet size of $110.21 \mathrm{~nm}$ and actual droplet size of $105.93 \pm 0.21 \mathrm{~nm}$. The desirability of the optimum KMO formulation was 1.00. This showed that the quality of the formulation was agreeable. A formulation with a droplet size of 105.93 will theoretically be able to penetrate the skin effectively to work on skin. At this range of droplet size, it is in good agreement with the previous study. A similar result was obtained by Azhar et al. (2018), with $110.01 \mathrm{~nm}$ as the minimum droplet size [22].

Table 6. Constraints of numerical optimization.

\begin{tabular}{cccc}
\hline & Goal & Lower Limit & Upper Limit \\
\hline PVA & In range & 20.00 & 30.00 \\
PG & In range & 1.00 & 10.00 \\
Shear rate & In range & 3000 & 9000 \\
Droplet size & Minimize & 111.1 & 163.5 \\
\hline
\end{tabular}

Abbreviations: PVA, polyvinyl alcohol; PG, propylene glycol.

Table 7. Optimum formulation of the KMO nanoemulsion formulation.

\begin{tabular}{cccccc}
\hline & \multicolumn{2}{c}{ Variables } & \multicolumn{2}{c}{ Droplet Size (nm) } & \multirow{2}{*}{ Desirability } \\
\cline { 1 - 4 } PVA & PG & Shear Rate & Actual & Predicted & \\
\hline 27.61 & 1.05 & 8656.17 & $105.93 \pm 0.21$ & 110.21 & 1.00 \\
\hline \multicolumn{5}{c}{ Abbreviations: PVA, polyvinyl alcohol; PG, propylene glycol. }
\end{tabular}

\subsection{Characterization of the Thin Film System (TFS)}

\subsubsection{Film Formation}

A uniform and complete thin film system was formed without the precipitation of the polymer on a glass slide. The KMO formulation had an opaque appearance on a glass slide before drying, but after drying, the film formed was transparent, dry, and non-sticky. The film was peelable and after the film was peeled from the glass slide, there was no residue of film left. 


\subsubsection{Drying Time}

A good TFS should have a minimum drying time to avoid a long waiting time for the patient [10]. Initially, the drying time of the KMO formulation containing 1\% (w/w) PVA and 1\% (w/w) PG was $15 \mathrm{~min}$, but as the percentage of PVA increased after optimization to $27.61 \%(w / w)$, the drying time became approximately $8 \mathrm{~min}$. This indicates that the amount of plasticizer decreased the drying time. In contrast, a formulation containing soybean extract as active and 17\% PVA as the plasticizer had a drying time range between 27 to $37 \mathrm{~min}$ [26]. This showed that the optimized formulation had a better drying time as the waiting time of patients would be less compared to the previous study.

\subsection{Physicochemical Characterization}

\subsubsection{Viscosity}

Shear-dependent behavior is one of the principal characteristics of non-Newtonian behavior observed in heterogeneous systems. There are two types of shear-dependent: shear thinning liquid shows a decrease in viscosity as the shear rate increases, while shear thickening liquid has an increasing viscosity with an increase in the shear rate. A power law index, $\mathrm{n}>1$ denotes that the sample is shear thickening; while $\mathrm{n}<1$ denotes that the sample is shear thinning and $\mathrm{n}=1$ shows a Newtonian, viscous behavior. Table 8 shows that the KMO formulation clearly displayed a shear thinning behavior as the flow index of $\mathrm{n}<1$ using the power law model. The shear thinning (pseudo-plastic) formulation exhibited a low viscosity fluid behavior (low resistance) to flow when tested under high shear conditions. The cosmetic and pharmaceutical industries usually demand shear thinning behavior for topical formulation products as they are easy to apply.

Table 8. Flow behavior indices (n), consistency coefficients $(k)$, and regression coefficients $\left(\mathrm{R}^{2}\right)$ of the KMO formulation in TFS.

\begin{tabular}{cccc}
\hline Formulations & $\mathbf{k}$ & $\mathbf{n}$ & $\mathbf{R}^{\mathbf{2}}$ \\
\hline KMO formulation & 1.1252 & 0.6803 & 0.8962 \\
\hline
\end{tabular}

\subsubsection{Particle Size, polydispersity index (PDI), and Zeta Potential}

Based on Table 9, the KMO formulation had a droplet size of $105.93 \pm 0.21 \mathrm{~nm}$, and a polydispersity index (PDI) $0.13 \pm 4.50 \times 10^{-3}$ and Zeta potential value of $-37.37 \pm 0.86 \mathrm{mV}$ were obtained. The nanoemulsion particle size should be between 20-200 $\mathrm{nm}$ for cosmetic applications [7]. The droplet size of $105.93 \pm 0.21 \mathrm{~nm}$ indicated that the $\mathrm{KMO}$ formulation would have better penetration of the KMO into the skin layers. Polydispersity (PDI) analyzes the size distribution, demonstrating the uniformity of the droplet size [34]. The good monodisperse system should have a PDI value lower than 0.5 [22] or lower than 0.25 [34]. As the PDI value of the KMO formulation was 0.13 , this indicated a good monodisperse system and is expected to be a stable emulsion. Zeta potential analyzes the electrokinetic potential of a particle and determines the stability of the formulation system. The formulation is considered stable when the value is more than $+25 \mathrm{mV}$ or lower than $-25 \mathrm{mV}$. The KMO formulation with a Zeta potential value of $-37.37 \pm 0.86 \mathrm{mV}$ demonstrated a higher electrostatic repulsion, which indicated that the nanoemulsion system was stable.

Table 9. Droplet size, PDI, Zeta potential, conductivity, and $\mathrm{pH}$ of the KMO formulation.

\begin{tabular}{ccc}
\hline Property & KMO Formulation & \% RSE \\
\hline Droplet Size $(\mathrm{nm})$ & $105.93 \pm 0.21$ & 0.11 \\
PDI & $0.13 \pm 4.50 \times 10^{-3}$ & - \\
Zeta potential $(\mathrm{mV})$ & $-37.37 \pm 0.86$ & - \\
Conductivity $(\mu \mathrm{S} / \mathrm{cm})$ & $7.47 \pm 4.05 \times 10^{-3}$ & - \\
$\mathrm{pH}$ & $4.74 \pm 0.02$ & - \\
\hline
\end{tabular}




\subsubsection{Transmission Electron Microscopy (TEM)}

Figure 4 represents the TEM image of the KMO formulation in the nanoemulsion size. The nanoemulsion was distributed almost uniformly and homogenously in the system. The droplet size analyzed from the TEM corresponded with the size obtained from the Zetasizer analysis. However, there were some large droplet sizes, as can be seen in Figure 4, which may be due to the Ostwald ripening occurrence, causing the enlargement of the droplet size.

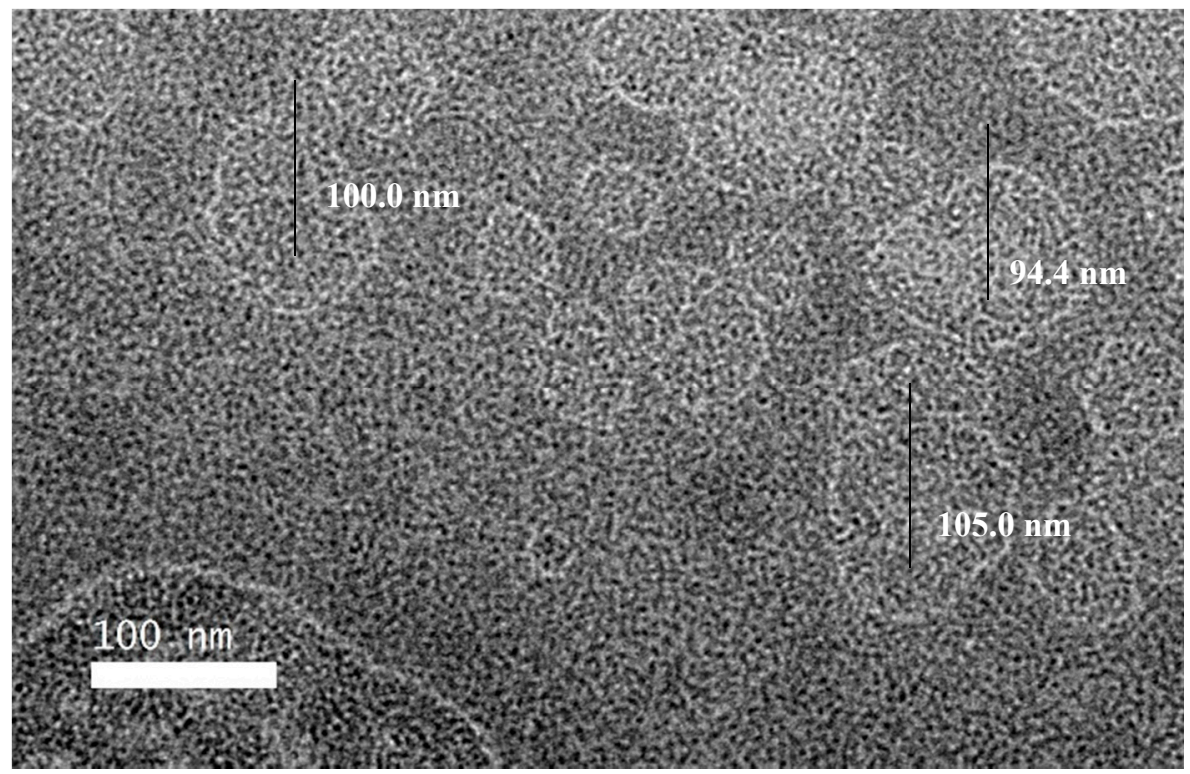

Figure 4. The TEM images of the KMO formulation from the $100 \mathrm{~nm}$ view.

\subsection{4. $\mathrm{pH}$ and Conductivity}

The $\mathrm{pH}$ values and conductivity of the KMO formulation are shown in Table 9. The $\mathrm{pH}$ measurement is vital as it needs to be between a range of 4.0 and 7.0 to be compatible with human skin [35]. However, others have reported the $\mathrm{pH}$ of skin normally ranges from 4 to 6 [36]. The $\mathrm{pH}$ value of the KMO formulation was $4.74 \pm 0.02$ (Table 9), indicating its suitability for use as a topical formulation.

The conductivity value refers to the number of free ions and water present in the system. From conductivity value, type of nanoemulsions can be investigated as either $\mathrm{O} / \mathrm{W}$ or W/O as high conductivity indicates that the aqueous phase is the continuous phase of the system, whereas the oil phase is nonconductive. Basically, the external phase determines the emulsion's conductivity. According to Mohamed et al. (2017), they mentioned that the O/W emulsion is conductive when the conductivity is $>0.00 \mu \mathrm{S} \cdot \mathrm{cm}^{-1}$, whereas the $\mathrm{W} / \mathrm{O}$ emulsion is nonconductive when the value is $\sim 0.00 \mu \mathrm{S} \cdot \mathrm{cm}^{-1}$ [37]. The KMO formulation had a conductivity of $7.47 \pm 4.05 \times 10^{-3}$, indicating an $\mathrm{O} / \mathrm{W}$ emulsion.

\subsubsection{Stability Study}

The KMO formulation remained in the homogenous phase even after 28 days. The actual color of the KMO formulation changed from white to a pale yellowish emulsion at day 28 , stored at $45^{\circ} \mathrm{C}$, which may be due to the reaction of any substance or ingredient in a formulation with the container at high temperature. Changes of color are not likely to happen due to enlargement of the droplet size as the droplet size measured was still below $200 \mathrm{~nm}$.

The evaluation of the optimized formulation on the creaming or sedimentation rate can be examined by the centrifugation test by analyzing the presence of phase separation. The KMO formulation was analyzed and it shows no phase separation after centrifugation at $4000 \mathrm{rpm}$ for $15 \mathrm{~min}$. This indicates the good stability of the KMO formulation. 
Figure 5 shows that the droplet size of the emulsion slightly increased from 107.35 to $122.95 \mathrm{~nm}$ at $45^{\circ} \mathrm{C}$, however, the formulation at all conditions was able to maintain its nanosize range between 20-200 nm. This shows the effectiveness of the xanthan gum in the nanoemulsion system to retain smaller droplet sizes and stability [22].

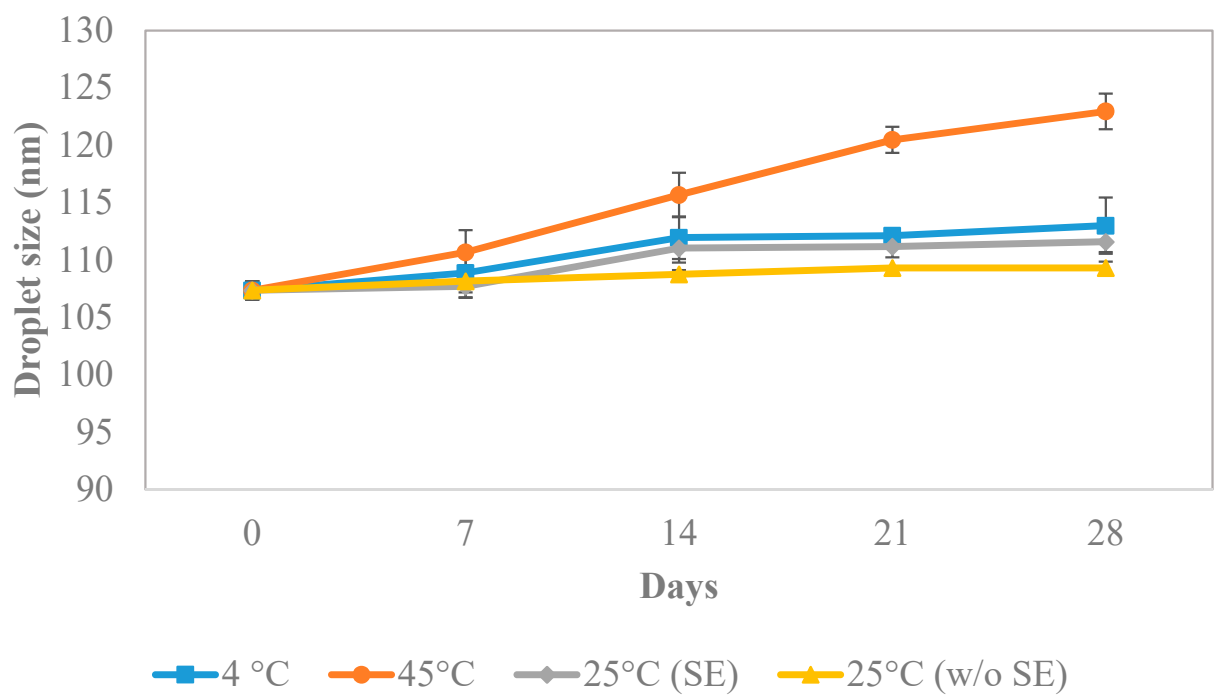

Figure 5. Graph of droplet size (nm) observed for 28 days under four different conditions (SE; sunlight exposure).

Coalescence is where two or more droplets fuse together and result in bigger droplets in the system. Figure 6 shows the plotted graph of $1 / \mathrm{r}^{2}$ vs. storage time (seconds) to determine the factor that affects the changes in droplet size over time. The graph with a linear relationship pattern suggests that the coalescence effect occurred in the system. However, based on the graph, all the droplet size values did not produce a linear pattern. Thus, the increase in droplet size over time was not created by coalescence.

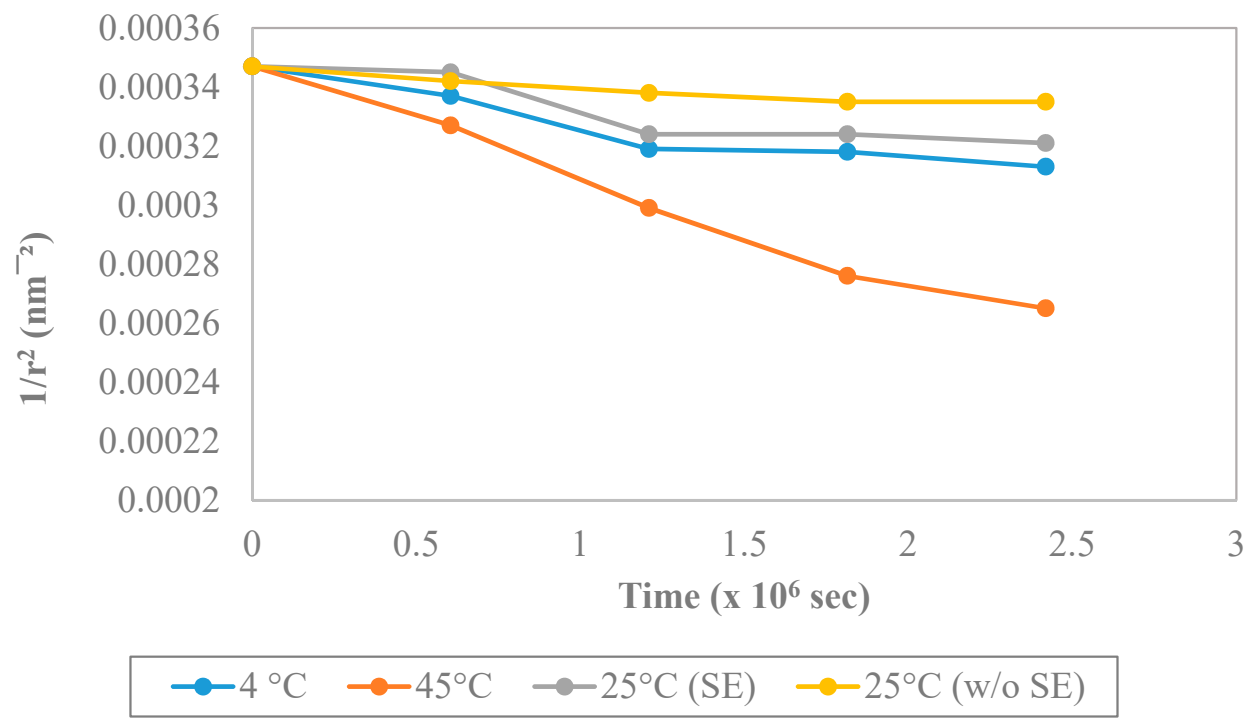

Figure 6. Graph of $1 / \mathrm{r}^{2}$ vs. storage time.

Ostwald ripening is the product of enlargement of droplet size due to the diffusion of the oil phase through the aqueous phase and can be investigated by plotting $\mathrm{r}^{3} \mathrm{vs}$. storage time (seconds). 
The KMO formulation under four different temperatures during 28 days of storage was affected by Ostwald ripening (Figure 7). A low Ostwald ripening effect can be seen during storage at $25^{\circ} \mathrm{C}$ as the droplet size increased slowly, while higher Ostwald ripening effect was identified at $45^{\circ} \mathrm{C}$ as the droplet size became larger, indicating the low stability of the nanoemulsion at a higher temperature.

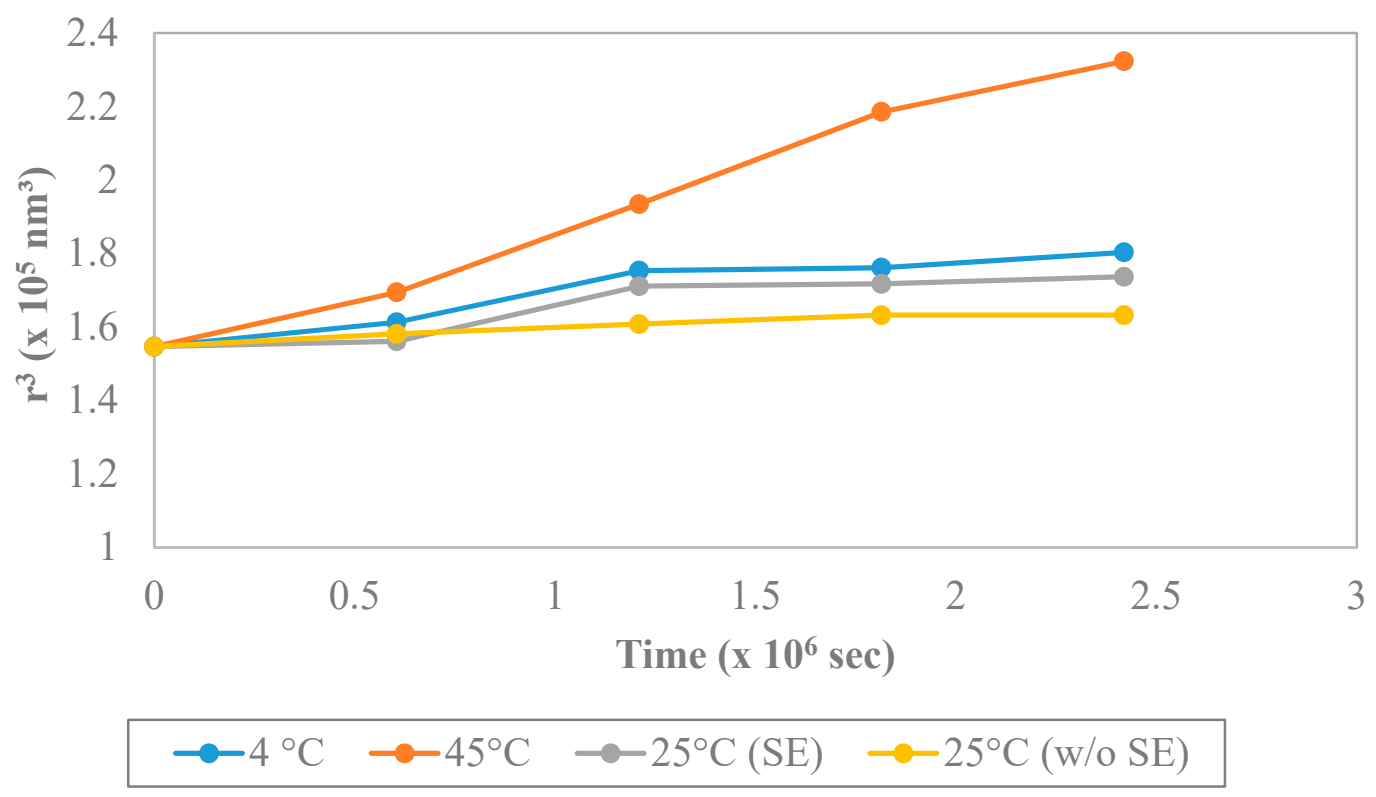

Figure 7. Graph of $\mathrm{r}^{3}$ vs. storage time (seconds).

\section{Conclusions}

In this study, a nanoemulsion formulation containing KMO in a thin film system was successfully developed. The droplet size of the KMO formulation was optimized using the RSM approach and characterized for its thin film system and physicochemical properties. The optimized KMO nanoemulsion formulation with desirable criteria was PVA $(27.61 \% w / w)$, PG $(1.05 \% w / w)$, and shear rate $(8656.17 \mathrm{rpm})$ with predicted droplet size $(110.21 \mathrm{~nm})$ and actual droplet size $(105.93 \mathrm{~nm})$ with a residual standard error $(\%$ RSE $)<2.0 \%$ was obtained. Analysis of variance showed that the fitness of the quadratic polynomial fit the experimental data with $F$-value (65.30), a low $p$-value $(p<0.0001)$, and a non-significant lack-of-fit. The optimized KMO formulation showed the desired criteria of a thin film system with flexible and peelable characteristics, is non-sticky, and has a short drying time of $7 \mathrm{~min} 25 \mathrm{~s}$, which shows its suitability for topical application as a peeling mask. The physicochemical properties (Zeta potential $-37.37 \mathrm{mV}$, PDI 0.13, $\mathrm{pH} 4.74$ ) and the stability of the KMO formulation under centrifugal force, and a stability study for 28 days at four different conditions of $4{ }^{\circ} \mathrm{C}, 25^{\circ} \mathrm{C}$ exposed to sunlight, $25^{\circ} \mathrm{C}$ protected from sunlight, and at $45^{\circ} \mathrm{C}$ showed the physical properties for cosmeceutical applications.

Author Contributions: N.F.J. performed the experiments, analyzed the data, and wrote the article. S.E.A. conceived and designed the experiments. R.M. and N.H.F. participated in the data analysis. The authors declare that they have no conflicts of interest in their authorship or publication of this contribution. All authors have read and agreed to the published version of the manuscript.

Funding: This work was carried out with the support of a grant provided by the Universiti Putra Malaysia (UPM), Malaysia (Innohub 9003251 and UPM-IPS 9673600).

Conflicts of Interest: The authors declare no conflict of interest. 


\section{References}

1. Ashari, S.E.; Mohamad, R.; Ariff, A.; Basri, M.; Salleh, A.B. Optimization of enzymatic synthesis of palm-based kojic acid ester using response surface methodology. J. Oleo Sci. 2009, 58, 503-510. [CrossRef] [PubMed]

2. Lajis, A.F.B.; Hamid, M.; Ariff, A.B. Depigmenting effect of kojic acid esters in hyperpigmented B16F1 melanoma cells. BioMed. Res. Int. 2012, 2012, 9. [CrossRef] [PubMed]

3. Yukuyama, M.N.; Ghisleni, D.D.M.; Pinto, T.D.J.A.; Bou-Chacra, N.A. Nanoemulsion: Process selection and application in cosmetics-A review. Int. J. Cosm. 2016, 38, 13-24. [CrossRef] [PubMed]

4. Kumar, M.; Bishnoi, R.S.; Shukla, A.K.; Jain, C.P. Techniques for Formulation of Nanoemulsion Drug Delivery System: A Review. Prev. Nutr. Food Sci. 2019, 24, 225-234. [CrossRef]

5. Nikam, T.H.; Patil, M.P.; Patil, S.S.; Vadnere, G.P.; Lodhi, S. Nanoemulsion: A brief review on development and application in Parenteral Drug Delivery. Adv. Pharm. J. 2018, 3, 43-54. [CrossRef]

6. Jaiswal, M.; Dudhe, R.; Sharma, P.K. Nanoemulsion: An advanced mode of drug delivery system. 3 Biotech 2015, 5, 123-127. [CrossRef]

7. Gutiérrez, J.M.; González, C.; Maestro, A.; Solè, I.M.; Pey, C.M.; Nolla, J. Nano-emulsions: New applications and optimisation of their preparation. Curr. Opi. Col. Interface Sci. 2008, 13, 245-251. [CrossRef]

8. Karki, S.; Kim, H.; Na, S.-J.; Shin, D.; Jo, K.; Lee, J. Thin films as an emerging platform for drug delivery. Asian J. Pharm. Sci. 2016, 11, 559-574. [CrossRef]

9. Frederiksen, K.; Guy, R.H.; Petersson, K. Formulation considerations in the design of topical, polymeric film-forming systems for sustained drug delivery to the skin. Eur. J. Pharm. Biopharm. 2015, 91, 9-15. [CrossRef]

10. Kathe, K.; Kathpalia, H. Film forming systems for topical and transdermal drug delivery. Asian J. Pharm. Sci. 2017, 12, 487-497. [CrossRef]

11. Budiman, A.; Aulifa, D.L.; Kusuma, A.S.W.; Kurniawan, I.S.; Sulastri, A. Peel-off gel formulation from black mulberries (Morus nigra) extract as anti-acne mask. Nat. J. Physiol. Pharm. Pharmacol. 2017, 7, 987-994. [CrossRef]

12. Velasco, M.V.R.; Vieira, R.P.; Fernandes, A.R.; Dario, M.F.; Pinto, C.A.S.D.O.; Pedriali, C.A.; Kaneko, T.M.; Baby, A.R. Short-term clinical of peel-off facial mask moisturisers. Int. J. Cosm. Sci. 2014, 36, 355-360. [CrossRef] [PubMed]

13. Lunter, D.; Daniels, R. In vitro Skin Permeation and Penetration of Nonivamide from Novel Film-Forming Emulsions. Ski. Pharmacol. Physiol. 2013, 26, 139-146. [CrossRef] [PubMed]

14. Aydar, A. Statistical Methods in Optimisation of Food Materials. Eur. Int. J. Sci. Tech. 2019, 8, 33-40.

15. Latha, S.; Sivaranjani, G.; Dhanasekaran, D. Response surface methodology: A non-conventional statistical tool to maximise the throughput of Streptomyces species biomass and their bioactive metabolites. Crit. Rev. Microbiol. 2017, 43, 567-582. [CrossRef] [PubMed]

16. Ong, S.T.; Ong, S.T.; Hung, Y.T.; Phung, Y.P. Application of conventional and statistical experimental methodology to optimise malachite green dye removal from aqueous solutions. Desalin. Water Treat. 2015, 55, 1359-1371.

17. Habib, S.; Ahmad, S.A.; Johari, W.L.W.; Shukor, M.Y.A.; Alias, S.A.; Khalil, K.A.; Yasid, N.A. Evaluation of conventional and response surface level optimisation of n-dodecane (n-C12) mineralisation by psychrotolerant strains isolated from pristine soil at Southern Victoria Island, Antarctica. Microbial. Cell Fact. 2018, 17, 44. [CrossRef]

18. Singh, S.K.; Singh, S.K.; Tripathi, V.R.; Khare, S.K.; Garg, S.K. Comparative one-factor-at-a-time, response surface (statistical) and bench-scale bioreactor level optimisation of thermoalkaline protease production from a psychrotrophic Pseudomonas putida SKG-1 isolate. Microbial. Cell Fact. 2011, 10, 114. [CrossRef]

19. Galooyak, S.S.; Dabir, B. Three-factor response surface optimization of nano-emulsion formation using a microfluidizer. J. Food Sci. Technol. 2015, 52, 2558-2571. [CrossRef]

20. Khan, M.J.H.; Hussain, M.A.; Mujtaba, I.M. Process parameters optimization for polypropylene production in a pilot scale fluidized bed catalytic reactor. In Proceedings of the Chemeca 2014: Processing Excellence; Powering Our Future, Perth, Australia, 28 September-1 October 2014; pp. 1393-1401.

21. Beringhs, A.O.; Rosa, J.M.; Stulzer, H.K.; Budal, R.M.; Sonaglio, D. Green Clay and Aloe Vera Peel-Off Facial Masks: Response Surface Methodology Applied to the Formulation Design. AAPS PharmSciTech 2013, 14, 445-455. [CrossRef] 
22. Azhar, S.N.A.S.; Ashari, S.; Salim, N. Development of a kojic monooleate-enriched oil-in-water nanoemulsion as a potential carrier for hyperpigmentation treatment. Int. J. Nanomed. 2018, 13, 6465-6479. [CrossRef] [PubMed]

23. Beringhs, A.O.; Dalmina, M.; Creczynski-Pasa, T.B.; Sonaglio, D. Response Surface Methodology IV-Optimal design applied to the performance improvement of an RP-HPLC-UV method for the quantification of phenolic acids in Cecropia glaziovii products. Rev. Bras. Farm. 2015, 25, 513-521. [CrossRef]

24. Ganz, M. Formulation and Evaluation of Hydrous and Anhydrous Skin Whitening Products Containing Sodium Ascorbyl pHospHate and Kojic Acid Dipalmitate. Doctoral Thesis, North-West University, Xian, Shaanxi, 2006.

25. Kulkarni, S.; Bairagee, D.; Choudhary, N. Formulation and Evaluation of activated charcoal peel off mask. Int. J. Phytopharm. Res. 2018, 9, 40-44.

26. Vieira, R.; Fernandes, A.R.; Kaneko, T.M.; Consiglieri, V.; Pinto, C.A.S.D.O.; Pereira, C.S.C.; Baby, A.; Velasco, M.R. Physical and physicochemical stability evaluation of cosmetic formulations containing soybean extract fermented by Bifidobacterium animalis. Braz. J. Pharm. Sci. 2009, 45, 515-525. [CrossRef]

27. Thottoli, A.K.; Achuthanunni, A.K. Effect of polyvinyl alcohol concentration on the ZnS nanoparticles and wet chemical synthesis of wurtzite ZnS nanoparticles. J. Nanostruct. Chem. 2013, 3, 31. [CrossRef]

28. Krishna, A.; Kumar, A.; Singh, R.K. Effect of Polyvinyl Alcohol on the Growth, Structure, Morphology, and Electrical Conductivity of Polypyrrole Nanoparticles Synthesized via Microemulsion Polymerization. ISRN Nanomater. 2012, 2012, 1-6. [CrossRef]

29. Oh, D.H.; Balakrishnan, P.; Oh, Y.-K.; Kim, D.-D.; Yong, C.S.; Choi, H.-G. Effect of process parameters on nanoemulsion droplet size and distribution in SPG membrane emulsification. Int. J. Pharm. 2011, 404, 191-197. [CrossRef]

30. Lyoo, W.S.; Cho, S.H.; Shin, D.S.; Han, S.S.; Park, C.S.; Kim, J.H.; Noh, S.K. Effect of processing parameters on the size and size distribution of high molecular weight atactic poly (vinyl alcohol) gel particles prepared by water-in-oil emulsion method using high pressure homogeniser. Polym. Polym. Compos. 2006, 14, 47-53. [CrossRef]

31. Safiah Mohamad, J.A.; Rozida, M.K.; Rizafizah, O. Coconut Oil Based Microemulsion Formulations for Hair Care Product Application. Sains Malays. 2019, 48, 599-605. [CrossRef]

32. Saberi, A.H.; Fang, Y.; McClements, D.J. Fabrication of vitamin E-enriched nanoemulsions by spontaneous emulsification: Effect of propylene glycol and ethanol on formation, stability, and properties. Food Res. Int. 2013, 54, 812-820. [CrossRef]

33. Suárez, M.J.; Lévy, H.; Lang, J. Effect of addition of polymer to water-in-oil microemulsions on droplet size and exchange of material between droplets. J. Phys. Chem. 1993, 97, 9808-9816. [CrossRef]

34. Marzuki, N.H.C.; Wahab, R.A.; Hamid, M.A. An overview of nanoemulsion: Concepts of development and cosmeceutical applications. Biotechnol. Biotechnol. Equip. 2019, 33, 779-797. [CrossRef]

35. Martínez-Pla, J.J.; Martín-Biosca, Y.; Sagrado, S.; Villanueva-Camañas, R.M.; Medina-Hernández, M.J. Evaluation of the $\mathrm{pH}$ effect of formulations on the skin permeability of drugs by biopartitioning micellar chromatography. J. Chromatogr. A. 2004, 1047, 255-262. [CrossRef] [PubMed]

36. Ali, S.; Yosipovitch, G. Skin pH: From Basic SciencE to Basic Skin Care. Acta Derm. Venereol. 2013, 93, $261-267$. [CrossRef]

37. Mohamed, A.I.; Sultan, A.S.; Hussein, I.A.; Al-Muntasheri, G.A. Influence of surfactant structure on the stability of water-in-oil emulsions under high-temperature high-salinity conditions. J. Chem. 2017, 2017, 1-11. [CrossRef]

(C) 2020 by the authors. Licensee MDPI, Basel, Switzerland. This article is an open access article distributed under the terms and conditions of the Creative Commons Attribution (CC BY) license (http://creativecommons.org/licenses/by/4.0/). 